\title{
Senior dental students' training on oral health care for geriatric patients: an interventional study
}

\author{
katayoun Sargeran, ${ }^{a, b}$ Simin Zahra Mohebbi, ${ }^{\text {a,b }}$ Zahra Chinipardaz, ${ }^{c}$ and Yaser Gurania
}

\author{
aDepartment of Community Oral Health, School of Dentistry, Tehran University of Medical Sciences, Tehran, Iran. \\ bResearch Center for caries prevention, Dental research institute, Tehran University of Medical Sciences, Iran. \\ 'Department of Periodontics, School of Dental Medicine, University of Pennsylvania, Philadelphia, Pennsylvania, USA. \\ Correspondence to, Simin Zahra Mohebbi (e-mail: smohebbi@sina.tums.ac.ir). \\ (Submitted: 09 July 2017 - Revised version received: 29 July 2017 - Accepted: 08 September 2017 - Published online: 26 December 2017)
}

\begin{abstract}
Objective We aimed to evaluate knowledge, attitude, and practice of senior dental students by providing a course entitled "Geriatric Oral Health Care" at Tehran University of Medical Sciences. The increasing population of the elders in both developed and developing countries highlights the importance of geriatric dental education.

Methods The intervention group $(n=68)$ filled in a self-administered questionnaire about their background, knowledge, attitude, and practice of geriatric oral health care before and after the course. The course consisted of lectures, group discussions, and oral health examination and instructions for elderly patients. The control group completed the same questionnaire without receiving any courses on geriatric oral health care. Statistical analysis was performed using t-test, one-way ANOVA, chi-square test, and linear regression modeling. Results Most of the participants (88.1\%) had previously treated elderly patients and $35.1 \%$ had the experience of living with the elders A considerable improvement was observed in both knowledge and self-reported practice of the students following the course $(P<0.05)$, while the students' attitude did not improve $(P>0.05)$.

Conclusions A short-term training program on geriatric oral health care has a great impact on the students' knowledge and practice, supporting the necessity of incorporating a geriatric dentistry course in the dental curriculum.

Keywords geriatric dentistry, oral health, dental education, dental students
\end{abstract}

\section{Introduction}

The aging population is increasing rapidly in all parts of the world. Over the next decades, the elderly population is expected to grow much more quickly than the total population due to advances in medical technology and improvements in health status. ${ }^{1-3}$ The annual rate of global population growth is estimated to be $1.2-2.4 \%$, while the fastest growing group is the age group 60 years old and older. ${ }^{4-6}$ It has been estimated that there will be 1.2 and 2 billion elderly people by 2025 and 2050 , respectively. ${ }^{5}$ Iran is facing a rapid expansion of the older population. The recent census has shown a remarkable increase in the percentage of aged people from $7.22 \%$ in 2006 to $8.20 \%$ in $2011 .^{3}$

As people grow old, systemic diseases can negatively influence their oral health. ${ }^{7}$ Consequently, the treatment decisions for older patients become more complex and challengeable for dentists. ${ }^{8}$ Today, older people wish to retain most of their teeth and they look for extensive and complicated dental treatments such as implants and complex restorations. ${ }^{9,10}$ So, there will be a growing demand for geriatric dental treatments. ${ }^{11}$

Several reports have investigated different barriers which could interfere with providing oral health care to older patients. ${ }^{12-14}$ Saunders et al. reported that the primary barriers to the expansion of geriatric dentistry at dental schools were the lack of trained faculty members, a crowded curriculum, and fiscal concerns. ${ }^{12}$ Multiple medical conditions, complexity of dental treatments in older patients, and insufficient training are other barriers, which result in dental practitioners' indecision to treat older patients. ${ }^{13,14}$

In 2005, the World Health Organization (WHO) recommended to provide oral health care professionals with educational courses on geriatric oral health. ${ }^{5}$ Some studies have demonstrated the efficacy of training courses on geriatric dentistry in dental practitioners. For example, Entwistle showed that the dentists' willingness to provide care for older people could be improved by adding geriatric care to the dental curriculum. ${ }^{15}$ Waldrop reported that dental students' knowledge of aging improved after one year of education in this subject. ${ }^{16}$ Another study emphasized the necessity of geriatric dentistry training courses at dental schools to address the needs of the vast elderly population in India. ${ }^{17}$ Also, findings of a recent investigation in Iran demonstrated that most of the dental students were unwilling to treat the elders and that they did not receive any specific training on geriatric dentistry. ${ }^{14}$

Therefore, it is important to provide training courses on geriatric oral health care for dental students in Iran. Unfortunately, the national curriculum of dentistry does not provide the students with sufficient knowledge and competency based education on geriatric dentistry. ${ }^{18}$ The aim of the present study was to assess the effect of implementing a short training course on "Geriatric Oral Health Care" on knowledge, attitude, and practice of senior dental students in Tehran.

\section{Methods}

\section{Ethics Approval}

Ethics approval was obtained from the Ethics Committee of School of Dentistry, Tehran University of Medical Sciences. Participation in the study was voluntary and the questionnaires were anonymous. Participants were informed about the objectives and protocol of the study. 


\section{Study Population}

Convenient sampling was used to include all senior dental students of Tehran University of Medical Sciences (TUMS) and Shahid Beheshti University of Medical Sciences (SBMU) during the 2015 academic year in this interventional study. The TUMS dental students were considered as the intervention group (total number $=68$, number of participants $=62$, response rate $91 \%$ ) and participated in a course entitled "Geriatric Oral Health Care", while the SBMU dental students (control group, total number $=73$, number of participants $=50$, response rate $68.5 \%$ ) did not take any courses in this regard.

\section{Variables of the Questionnaire}

We developed a self-administered questionnaire based on previously validated questionnaires. ${ }^{19,20}$ The questionnaire was evaluated for content validity by five faculty members from the Department of Community Oral Health at TUMS. A pilot study was performed amongst ten sixth-year dental students in order to check the reliability of the questionnaire. A Cronbach's alpha coefficient greater than 0.7 confirmed good internal consistency.

The questionnaire was composed of the following sections: background information, general knowledge and attitude towards aging and the elders, knowledge and attitude towards providing oral health care for elderly patients, and the students' self-reported geriatric oral health care practice.

Background questions included age, gender, marital status, Grade Point Average (GPA), living place (with parents/ in the dormitory/ living independently), prior experience of living with the elders (yes/no), and prior experience of treating elderly patients (yes/no).

The first section consisted of 14 questions in order to assess the students' knowledge of geriatrics. The following statements are examples of this section: less time is available to plan for the elderly population in poor countries, women have a longer life-expectancy, clinical decision making for elderly patients should be based on their health and physical ability rather than their chronological age, aging causes an increase in heart beats and a decrease in respiratory capacity, etc.

The second section, knowledge of oral health care for elderly patients, included 16 question which targeted the students' knowledge about various subjects such as the growing trend of aging in Iran, the necessity of being familiar with common geriatric diseases for successful dental practice, reducing oral cancer in the elders through preventive measures, comprehensive oral health instructions, special considerations during dental treatment, and appropriate cooperation between dental and medical team. In the knowledge sections, the provided answers were 'yes', 'no' and 'I don't know'.

The third section, attitude towards aging, contained 13 questions such as "I prefer to treat young patients rather than old ones", "Taking care of the older people is a social responsibility", "Geriatric medical care needs a large amount of financial resources", "The elderly generally engage less in social activities", "It is interesting for me to listen to the elder's experiences", and "I understand older patients more than younger ones".

Four questions measured the students' attitude towards providing oral health care for geriatric patients as follows: "More attention should be paid to treatment needs in the elderly population", "Tooth loss is a consequence of aging", "Providing preventive oral care for geriatric patients is not profitable for dentists" and "Providing preventive oral care for geriatric patients is economically beneficial to the society". The responses in the attitude sections were categorized on a Likert scale from "strongly agree" to "strongly disagree", including "I don't know".

The last section measured the students' practice of oral health care in the elderly patients through four questions with multiple-choice answers: "How often should elderly patients with xerostomia visit a dentist?", "What would you do to deal with patients who take multiple drugs for their systemic disease?", "Do you check the blood pressure of the elderly patients before starting treatment?" and "What do you consider in treating patients with arthritis?".

\section{Study Design and Intervention Description}

"Geriatric Oral Health Care" training was conducted in three sessions during a one-week period for students in the intervention group, as part of their community oral health practical course. In the first session, the educational content was delivered using lecture and Problem Based Learning (PBL) methods by two lecturers from the Department of Community Oral Health, TUMS. The students were asked to fill in the selfadministrated questionnaire prior to the intervention. Educational topics were related to geriatrics and geriatric oral health (45 minutes each). Afterward, a paper-patient was introduced to the class by a Power Point presentation. All the students discussed the case with each other in small groups (5 students in each group). At the end of the first session, the groups presented their answers and discussed them with their classmates and teachers.

In the second session, the students attended a municipal health center in Tehran, where the elders were invited to receive oral health examination and education. The students examined the participants in order to determine their oral health status and oral treatment needs. Meanwhile, each student explained oral hygiene and denture care instructions to the patient. During the session, the students' performance and skills were evaluated with a "Direct Observation of Procedural Skills" (DOPS) checklist by two faculty members and a general dentist.

In the last session, the students gave presentations on their field observations and experiences and had discussions with classmates and teachers. The session was ended with final conclusions and the students were asked to fill in the same self-administrated questionnaire and the course satisfaction form. The control group completed the same questionnaire twice within a week without receiving any education regarding geriatric oral health care.

\section{Statistical Analysis}

We dichotomized answers to all the questions. A positive response in attitude sections and a correct response in knowledge and practice sections received a score of 1 while false/ negative/I don't know the answers were assigned a score of 0 . The scores were calculated on a scale of 0-100 in each section of the questionnaire. Then, the total score was calculated for knowledge, attitude, and practice sections in the pre-test and post-test for each participant in intervention and control groups.

The obtained data were analyzed using SPSS version 18 . T-test and one-way ANOVA were used to compare mean values, and the chi-square test was employed to compare frequency between the two groups. Linear regression models were conducted for the multivariate assessment to control the effects of confounders. $P$ values less than 0.05 were considered significant. 


\section{Results}

\section{Sample Description}

The study population comprised 112 students, 69 (61.6\%) female students and $43(38.4 \%)$ male students. The mean age of the students was 24.2 years (range: $22-28$ ) in the intervention group and 25.42 years (range: $23-40$ ) in the control group. Out of 68 students in the intervention group, 62 students completed the questionnaire (response rate $=$ $91 \%$ ) while the response rate was $68.8 \%$ in the control group (of 73 distributed questionnaires, 50 questionnaires were returned).

Most of the participants (88.1\%) reported that they had prior experience in treating elderly patients, whereas the rest of them (11.9\%) did not have any experience in this regard. In terms of living with the elders, only $35.1 \%$ of the students had ever lived with. Except for age, the intervention and control groups were similar in background variables (Table 1).

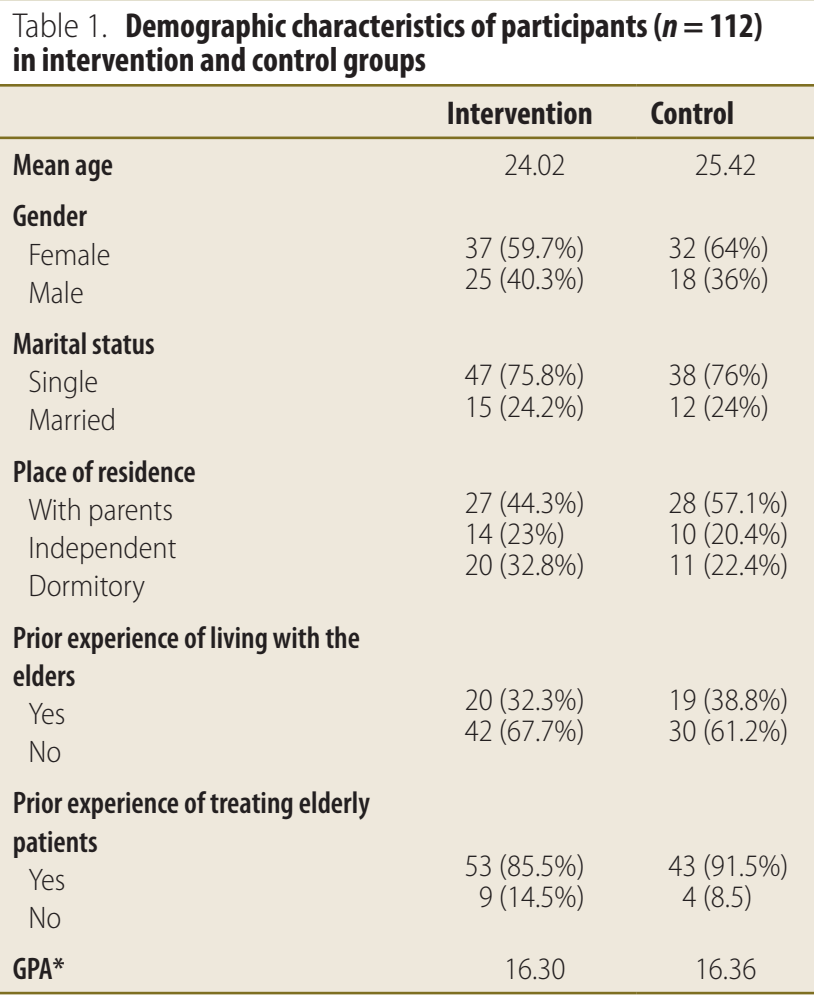

${ }^{*}$ Grade Point Average.

\section{Educational Intervention Findings}

The mean score of general knowledge towards aging and elders was 73.5 and 86.1 in the intervention and control group at baseline, respectively. These scores increased to 91.7 and 87.6 after the intervention. The baseline score of the students' knowledge about providing geriatric oral health care in the intervention group was 55 which increased to 96.1 after the intervention. In the control group, this score increased from 83.2 to 84.4. There was a significant difference in the knowledge score in both knowledge sections between the two groups after the intervention $(P<0.05)$.

The mean score of the students' attitude towards geriatrics was 68.3 and 67.8 in the intervention and control group, respectively, which increased to 69.2 and 69.3 after the intervention. The mean baseline score of the students' attitude towards providing geriatric oral health care was 76.4 and 73.6 in the intervention and the control group respectively which increased to 80.3 in the intervention group and 75.6 in the control group after the intervention. The groups showed no significant differences in the attitude towards geriatrics $(P=0.55)$ and attitude regarding geriatric oral health care $(P=0.33)$ after the intervention.

The baseline score of the students' self-reported oral health care practice for the elderly patients was 31.4 and 45 in the intervention and control group, respectively. After the intervention, the score significantly increased to 89.5 in the intervention group and to 47 in the control group after the intervention $(P=0.00)$.

Linear regression analysis was used to assess the effect of background variables on the changes of the students' knowledge, attitude and practice. No significant relationship was detected between changes in the students' practice and background variables $(P>0.05)$. The key factor in changing the students' knowledge was the intervention (Table 2). Another model revealed that having the experience of treating elderly patients was effective in changing the attitude of the participants (Table 3).

\section{Discussion}

The growth of the elderly population is inevitable. ${ }^{3}$ This demographic transition stimulates dental schools to train dental students in geriatric oral health care ${ }^{21}$ so that the students feel competent in treating elderly patients. ${ }^{22}$ The current study evaluated the effect of a short-term training program on "Geriatric Oral Health Care" on senior dental students in Iran.

\begin{tabular}{lcccc}
\hline Table 2. Association between changes in knowledge and background factors in participants $(\boldsymbol{n}=\mathbf{1 1 2}$ ) after the educational intervention \\
\hline & B & Std. error & Beta & $\boldsymbol{P}$-value \\
\hline - Intervention/control groups & 2.0 & 0.29 & 0.61 & 0.00 \\
- Gender (male/female) & 0.67 & 0.43 & 0.16 & 0.12 \\
- Age & 0.22 & 0.09 & 0.02 & 0.81 \\
- Marital status (single/married) & 0.71 & 0.51 & 0.14 & 0.16 \\
- Prior experience of living with the elders (yes/no) & 0.35 & 0.50 & 0.08 & 0.47 \\
- Prior experience of treating elderly patients (yes/no) & 0.79 & 0.65 & 0.12 & 0.22 \\
- GPA & 0.09 & 0.19 & 0.05 & 0.61 \\
- Place of residence (with parents/dormitory/independent) & 0.42 & 0.23 & 0.18 & 0.07
\end{tabular}




\begin{tabular}{lcccc}
\hline Table 3. Association between changes in attitudes and background factors in participants $(\boldsymbol{n}=\mathbf{1 1 2}$ ) after the educational intervention \\
\hline & B & Std. error & Beta & $\boldsymbol{P}$-value \\
\hline - Intervention/control groups & 0.002 & 0.90 & 0.01 & 0.98 \\
- Gender (male/female) & 1.48 & 0.87 & 0.17 & 0.09 \\
- Age & 0.09 & 0.19 & 0.05 & 0.63 \\
- Marital status (single/married) & 1.43 & 1.04 & 0.14 & 0.17 \\
- Prior experience of living with the elders (yes/no) & 0.92 & 1.01 & 0.10 & 0.36 \\
- Prior experience of treating elderly patients (yes/no) & 2.66 & 1.31 & 0.20 & 0.04 \\
- GPA* & 0.29 & 0.38 & 0.07 & 0.44 \\
- Place of residence (with parents/dormitory/independent) & 0.39 & 0.47 & 0.08 & 0.41 \\
\hline
\end{tabular}

Our results revealed that such training interventions were significantly effective in enhancing the students' knowledge about and practice of geriatric oral health care despite the students' attitude did not improve significantly.

In the present study, the students' knowledge was evaluated in two parts: general knowledge about geriatrics, and knowledge about providing oral health care for elderly patients. The students presented a good level of knowledge in the first part and a moderate level in the second part. We found no study evaluating the second part for comparison. However, the results of studies by Fabiano et al. ${ }^{19}$ and Waldrop et al. ${ }^{16}$ demonstrated the low level of students' knowledge about aging. Friedman and Brecknock reported that dental and dental hygiene students' knowledge was inadequate and did not significantly change as reported by similar studies in the 1980s and 1990s..$^{23}$ Moreover, Wood and Millgan reported that the students' knowledge of aging did not change and seemed to have even declined in comparison with the past years. ${ }^{24}$ The poor knowledge of dental students regarding aging was reported by Visschere et $\mathrm{al}^{25}$ they mentioned it could be probably due to the lack of a special course in geriatric dentistry at most dental schools.

Our finding on the improvement of the students' knowledge after educational intervention is in agreement with some other studies. ${ }^{26,27}$ Teasdale and Shaikh conducted a CD-based educational tool to train students in geriatric oral health. They found that a self-instructional e-learning tool was effective in enhancing the students' knowledge. ${ }^{28}$ On the contrary, Fabiano et al. pointed out that dental students' knowledge was not improved following the educational intervention; however, they recognized issues that prevented the patients' compliance and affected the oral health of the elderly patients. ${ }^{19}$

In the present study, the participants showed a moderate level of positive attitude towards aging and geriatric oral health care. This finding is in agreement with the results of a study conducted by Gupta et al. that showed students at the University of California, Los Angeles (UCLA) had a relatively positive attitude towards the geriatric population. ${ }^{29}$ Furthermore Nochajski et al. showed that in general, dental students displayed a modestly positive attitude towards older adults in three of the four scales (Integrity, Autonomy, Acceptability) and a relatively more negative attitude in the fourth (Instrumentality). ${ }^{30}$ However, the findings of an investigation in Belgium showed that the attitude of recently graduated dentists towards the institutionalized elderly people was rather negative. ${ }^{25}$ On the other hand, Sadaf \& Yazdanie showed that the dental students' attitudes were very positive towards elderly patients and they showed a strong desire to treat them. ${ }^{3}$
They concluded that geriatric dentistry should be introduced as a separate subject in the curriculum to properly utilize the students' positive attitudes and improve the quality of life of the elders.

There was no significant difference between pre- and post-test scores in attitude sections, which showed that educational intervention did not have any impacts on the students' general attitude towards aging and geriatric oral health care. This result is in accordance with the findings of prior studies. Claus reported that training programs in geriatric dentistry failed to make a significant change in the dental students' attitude towards the elders. ${ }^{32}$ According to De Visschere et al., geriatric dentistry education in the undergraduate curriculum did not appear to influence the recently graduated dentists' attitude towards the institutionalized elderly people. ${ }^{25}$

Although the majority of the participants had the experience of treating elderly patients, most of them did not prefer to provide oral health care for them. This may be due to the fact that senior dental students are often under pressure to meet their clinical requirements for graduation, so they prefer to select patients with minimal dental needs. This point has been mentioned in other reports, as well. ${ }^{27,33}$

The participants' score of self-reported oral health care practice for the elders was low. Following the educational intervention, the score improved markedly in the intervention group. Unfortunately, we found no study in this regard for comparison. However, our finding indicates the great impact of educational intervention on the students' perceived practice for elderly patients.

The current study was an educational trial with a control group, which is the most powerful study design. The intervention and control groups were not different in demographic factors except for the mean age, which was slightly higher in the control group. Additionally, the national dentistry curriculum is similar in all dental schools in Iran and no courses were available on geriatric oral health care at the time of the study. The measurement tool for attitude assessment was developed based on previous validated questionnaires; however, we tested the validity and reliability of the questionnaire once more. We asked the students to use a code instead of their personal information in order to improve the validity of the answers and decrease the possibility for errors.

This study had some limitations. The loss of participation for getting post-test was occurred in the control group, may be as a result of lack of motivation to take the post-test. Also, the questionnaire was self-administrated and some questions were occasionally left unanswered. Finally, there was a short 
period of time between pre- and post-tests. Since the students were in their final semester, long-term evaluation of the educational intervention was impossible. Nonetheless, it could be the topic of further researches in this field.

\section{Conclusions}

While the attitude of dental students did not change following a short-term training program on geriatric oral health care, their knowledge and self-reported practice improved markedly. It seems that long-term training and other educational methods should be used to form a positive attitude towards geriatric oral care in dental students.

\section{Acknowledgements}

We would like to express our gratitude to head and staff of the municipal health centers in Tehran contributed to this work.

\section{Conflict of Interest}

None.

\section{References}

1. Grigsby JS. Paths for future population aging. Gerontologist. 1991;31: 195-203.

2. Treas J, Logue B. Economic development and the older population. Popul Dev Rev. 1986;12:645-673.

3. Noroozian M. The Elderly population in Iran: An ever growing concern in the health system. Iran J Psychiatry Behav Sci. 2012;15:6:1-6.

4. United Nations, Department of Economic and Social Affairs, Population Division (2015). World Population Ageing 2015 (ST/ESA/SER.A/390). http:// www.un.org/en/development/desa/population/publications/pdf/ageing/ WPA2015_Report.pdf. Accessed 13 December 2016.

5. Petersen PE, Yamamoto T. Improving the oral health of older people: the approach of the WHO Global Oral Health Programme. Community Dent Oral Epidemiol. 2005;33:81-92

6. Holm-Pedersen P, Walls A, Ship J. Text book of geriatric dentistry. 3rd ed. Wiley Blackwell, 2015

7. Ghezzi EM, Ship JA. Systemic diseases and their treatments in the elderly: impact on oral health. J Public Health Dent. 2000;60:289-296.

8. Kotzer RD, Lawrence HP, Clovis JB, Matthews DC. Oral health-related quality of life in an aging Canadian population. Health Qual Life Outcomes. 2012;10:50.

9. Ettinger RL, Mulligan R. The future of dental care for the elderly population. J Calif Dent Assoc. 1999;27:687-692.

10. Eklund SA. Changing treatment patterns. J Am Dent Assoc. 1999;130: 1707-1712.

11. Issrani R, Ammanagi R, Keluskar V. Geriatric dentistry-meet the need. Gerodontology. 2012;29:e1-e5.

12. Saunders RH, Yellowitz JA, Dolan TA, Smith BJ. Trends in predoctoral education in geriatric dentistry. J Dent Educ.1998;62:314-318.

13. Patil Manashvini S, Patil Sanjayagouda B. Geriatric patient - psychologica and emotional considerations during dental treatment. Gerodontology. 2009;26:72-77.

14. Hatami B, Ahmady AE, Khoshnevisan MH, Lando HA. Dental Students Perceived Barriers in Geriatric Dental Care Active Involvement. Oral Health Dent Manag. 2014;13:675-679.

15. Entwistle BA. Oral health promotion for the older adult: implications for dental and dental hygiene practitioners. J Dent Educ. 1992;56:636-639.

16. Waldrop DP, Fabiano JA, Nochajski TH, Zittel-Palamara K, Davis EL, Goldberg LJ. More than a set of teeth: Assessing and enhancing dental students' perceptions of older adults. Gerontol Geriatr Educ. 2006;27:37-56.

17. Shah N. Need for gerodontology education in India. Gerodontology. 2005:22:104-105.
18. Dental education program in dental schools of the Islamic Republic of Iran (1st ed) Tehran: Ministry of Health and Medical Education, Council for Dental and Sub-dental Eduation, 2000.

19. Fabiano JA, Waldrop DP, Nochajski TH, Davis EL, Goldberg LJ. Understanding dental students' knowledge and perceptions of older people: toward a new model of geriatric dental education. J Dent Educ. 2005;69:419-433.

20. Stewart TJ, Roberts E, Eleazer P, Boland R, Wieland D. Reliability and validity issues for two common measures of medical students' attitudes toward older adults. Educ Gerontol. 2006;32:409-421.

21. Mendoza-Núñez VM, de la Luz Martínez-Maldonado M, Correa-Muñoz E. Perceptions on the importance of gerontological education by teachers and students of undergraduate health sciences. BMC Med Educ. 2007;7:1.

22. Mohammad AR, Preshaw PM, Ettinger RL. Current status of predoctoral geriatric education in US dental schools. J Dent Educ. 2003;67:509-514.

23. Friedman PK, Brecknock SA. Comparison of dental and dental hygiene students' performance on "Facts of Aging Quiz". J Mass Dent Soc. 2003;52:36-39.

24. Wood GJ, Mulligan R. Cross-sectional comparison of dental students' knowledge and attitudes before geriatric training, 1984-99. J Dent Educ. 2000:64:763-771.

25. De Visschere L, Van Der Putten GJ, De Baat C, Schols JG, Vanobbergen J. The impact of undergraduate geriatric dental education on the attitudes of recently graduated dentists towards institutionalised elderly people. Eur J Dent Educ. 2009;13:154-161.

26. Broder $\mathrm{H}$, Block MJ. Effects of geriatric education on the knowledge of dental students. Spec Care Dentist. 1986;6:177-179.

27. Anehosur GV, Nadiger RK. Evaluation of understanding levels of Indian dental students' knowledge and perceptions regarding older adults. Gerodontology. 2012;29:e1215-e1221.

28. Teasdale TA, Shaikh M. Efficacy of a geriatric oral health CD as a learning tool. J Dent Educ. 2006;70:1366-1369.

29. Gupta S, Venkatraman S, Kamarthi N, Goel S, Goel S, Keswani T. Assessment of the attitude of undergraduate dental students toward the geriatric population. Trop J Med Res. 2014;17:104-108.

30. Nochajski TH, Waldrop DP, Davis EL, Fabiano JA, Goldberg LJ. Factors that influence dental students' attitudes about older adults. J Dent Educ. 2009;73:95-104.

31. Sadaf A, Yazdanie N. Attitude of dental students towards elderly. Pakistan Oral Dent J. 2012;32:176-179.

32. Claus LM. Dental student attitudes towards the elderly and training in geriatric dentistry. Int Dent J. 1982;32:371-378.

33. Chowdhry N, Aleksejuniene J, Wyatt C, Bryant R. Dentists' perceptions of providing care in long-term care facilities. J Can Dent Assoc. 2011;77:b21.

This work is licensed under a Creative Commons Attribution-NonCommercial 3.0 Unported License which allows users to read, copy, distribute and make derivative works for non-commercial purposes from the material, as long as the author of the original work is cited properly. 